\title{
Methods to our madness
}

\author{
ALLAN JACOBSON \\ Department of Microbiology and Physiological Systems, University of Massachusetts Medical School, Worcester, Massachusetts 01655-0122, USA
}

Though this be madness, yet there is method in't. William Shakespeare, Hamlet

In the last 20 years we have witnessed an explosion in our understanding of the ways and means of post-transcriptional control. Novel modes of regulation by and for RNAs of all sizes and shapes have become routine news to a world once dominated by that other nucleic acid, DNA. Not anymore. RNA is God now. To appreciate how that happened, let's consider mRNA. When it came to studying mRNA 1995 was so 20th century, so much your father's Oldsmobile. If you needed to know if an mRNA was present in a sample you'd run a northern, do RT-PCR, or translate it in vitro. To know if it was functional in vivo you'd analyze a polysome gradient. To localize something bound to it, a toeprint. To obtain primary sequence? Generate a cDNA clone and sequence that. And if the mRNA in question just happened to be of low abundance, forget everything I just said. All that began to change just as the journal RNA was born. It was the beginning of the genomics era and fabulous new tools were being applied to genome sequencing and multiple aspects of gene expression analysis. The collection of new methods that now allows us to think about RNA in ways unforeseen has continued to improve, continued to provide higher and higher resolution, and to do so in ways that are often affordable for most labs. To me, the new methods have provided the RNA community with its Mars landers, supercolliders, and Hubble telescope needed to figure out what's actually going on. Let's consider a few of them.

Nothing typified the excitement of the early days of the new era more than the arrival of microarray analysis as a tool with the potential for simultaneous assessment of the expression of thousands of genes from virtually any sample. Although initially dependent on a robotic printer and cDNA clones, commercial applications utilizing light-directed synthesis of high density oligonucleotide arrays and post-hybridization laser confocal fluorescence scanning followed within a few years, as did the more comprehensive coverage of tiling arrays. For mRNA biologists, applications of the method have ranged from straightforward

\footnotetext{
Corresponding author: allan.jacobson@umassmed.edu

Article and publication date are at http://www.rnajournal.org/cgi/doi/ $10.1261 /$ rna.049684.115. Freely available online through the RNA Open Access option.
}

analysis of the changes in mRNA levels in response to various stimuli, to quantitation of different pre-mRNA processing variants, or the discovery of novel and previously unannotated transcribed sequences. PubMed's listing of almost 63,000 references in response to the query "microarray analysis of gene expression" certainly attests to the utility and popularity of microarray methods that continue to generate useful data for basic biology, disease investigation, and drug development.

Given the hybridization-selection basis of microarray analysis, most data derived from it provides information on populations of molecules and is still of limited value for low abundance transcripts. Enter the solution to those problems (and many others): next-generation sequencing and its ability to provide transcriptome analytics for sequenced genomes at single nucleotide resolution. The techniques empowered by this advance, and parallel developments in bioinformatics, have made it possible to take gene expression analysis to another level. Notably, RNA-Seq and similar approaches have provided much more refined genome annotations than previously available, uncovered pervasive intergenic transcription, identified novel genes, transcripts (coding and noncoding), and splicing/polyadenylation events, and allowed highly accurate quantitation of a wide range of mRNA expression levels.

As powerful and informative as the sequencing-related methods have been, long-sought insights have depended in part from a combination of those methods with additional steps. Thus, for example, the amalgamation of RNA-Seq with RNA-protein crosslinking and proteomics has clarified the nature of mRNP architecture, and RNA-Seq combined with selective nucleotide modification uncovered hundreds of mRNA pseudouridylation sites. But it's ribosome profiling, Ingolia and Weissman's procedure for deep sequencing of ribosome-protected fragments, that has left mRNA aficionados ecstatic about our new understanding of the cell's translation landscape. Not only does the method resolve ongoing protein synthesis so well that its data manifests 3-base periodicity, but in just five years it has been sufficiently versatile to identify the starts and stops of novel open reading frames, reveal unanticipated uORFs, elongation pauses,

(C) 2015 Jacobson This article, published in RNA, is available under a Creative Commons License (Attribution-NonCommercial 4.0 International), as described at http://creativecommons.org/licenses/by-nc/4.0/. 
translated lincRNAs, and nonsense codon readthrough events, derive elongation rates, elucidate localized translation, facilitate an understanding of the significance of poly(A) tail heterogeneity, clarify the consequence of miRNA-mediated repression, and on and on.

This embarrassment of riches is, of course, much broader and extends to many other methods. We can visualize the spatial and temporal regulation of individual mRNAs in isolated cells, derive atomic level structures of ribosomal complexes by cryo-EM, monitor the dynamics of splicing or protein synthesis at the single molecule level, or identify small molecule modulators of key RNA-driven reactions. I could continue, but the message is simple: When I think about progress in RNA research for the last 20 years, I get most excited about the methods that are allowing us to ask better questions and get more meaningful (and occasionally mindblowing) answers. May the madness continue.

\section{Acknowledgments}

I thank Feng He and Bijoyita Roy for helpful discussions and the National Institutes of Health for a research grant (R37 GM2775735) to my laboratory. 

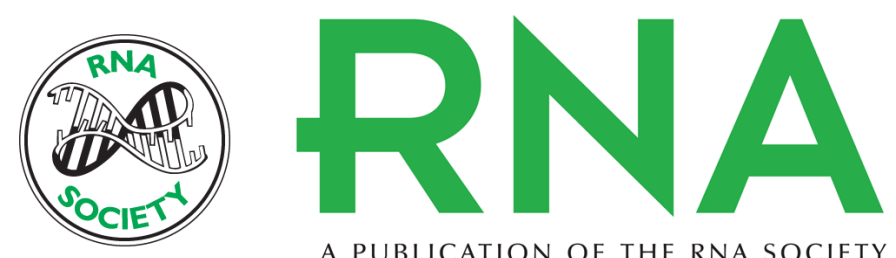

A PUBLICATION OF THE RNA SOCIETY

\section{Methods to our madness}

Allan Jacobson

RNA 2015 21: 529-530

Open Access Freely available online through the RNA Open Access option.

Creative This article, published in $R N A$, is available under a Creative Commons License Commons (Attribution-NonCommercial 4.0 International), as described at License http://creativecommons.org/licenses/by-nc/4.0/.

Email Alerting Receive free email alerts when new articles cite this article - sign up in the box at the Service top right corner of the article or click here. 